\title{
An analysis of dynamics of a change in the electricity intensity of the economy of the country and eastern regions and the forecasting of electricity consumption in the long term
}

\author{
Anatoliy Korneev ${ }^{1, *}$ \\ ${ }^{1}$ Energy Systems Institute of Siberian Branch of the Russian Academy of Sciences, 664033 Lermontov str., 130, Irkutsk, Russia
}

\begin{abstract}
The paper presents a retrospective analysis of the trends towards changes in the electricity intensity of the economy of Russia and its eastern regions and assesses the dynamics of its change in the long term. The macroeconomic forecast of Russia's economic development is given and the forecast of electricity consumption is made for the country and its eastern regions.
\end{abstract}

\section{Introduction}

The eastern regions of Russia, including the Entities of the Russian Federation in the Siberian Federal District (SFD), with focus on the regions of Eastern Siberia, and the Entities of the Russian Federation in the Far Eastern Federal District (FEFD), have a rich natural resource potential for economic development. This is, first of all, mining and processing industry, that requires advanced development of production and social infrastructure. The development of such an infrastructural industry as electric power industry occupies a special place in terms of power supply to electricity intensive productions. In this regard, it is essential for the eastern regions to forecast their electricity needs. The level of electricity consumption will depend on the growth rates of their economy and on the electricity intensity of the production.

The electricity intensity of the products (specific electricity consumption) is the most important parameter for all prospective forecasts of electricity consumption: short-term, medium-term and long-term. Depending on the forecasting period and the quantitative composition of industries, the electricity intensity may have a different degree of aggregation. In the models of forecasting the economy and power consumption with a large number of activities, which is typical of short- and mediumterm periods, the prospective electricity intensity is estimated according to the types of activity. This allows us to more specifically consider the influence of various factors on the level of the prospective electricity intensity of a particular activity. For the long-term forecasting, however, and especially for the periods of 30 or more years, the economic activities can be aggregated up to the production of GRP due to the high uncertainty of the impact of various factors on the electricity intensity [1]. In this case, electricity intensity $(e)$ is calculated as a ratio of the total electricity consumption $(E)$ by the

\footnotetext{
* Corresponding author: korn@isem.irk.ru
}

economy to the total volume of the produced gross regional product $(P)$ in year $t$ :

$$
e(t)=E(t) / P(t)
$$

The macroforecast in comparison with the detailed multi-sectorial forecast of gross regional product has both advantages and disadvantages. However, many of the macroforecast disadvantages associated with the high aggregation of the economy and its electricity intensity are largely overcome by constructing the scenarios for the future economic development based on retrospective trends and their prospective assessment.

\section{Scenarios for the national economic development for the long term future}

Based on the state and trends in the national economic development over the past 15 years, we can consider two main scenarios for the long-term economic development: a 'no-change' scenario (I) and a moderately optimistic scenario (II). In the 'no-change' scenario, the economy of Russia will develop under the following conditions:

- orientation to the external raw-material market;

- various types of sanctions associated with geopolitical and economic competition with the leading developed countries;

- world financial and economic crises, recurring approximately every $8-10$ years, caused, as a rule, by the interaction of various money and credit factors $[2,3]$;

- limited internal and external investment and their unstable growth rates due to recurring world crises;

- a slow, sluggish transition to effective technologies and innovative implementations that require large investment.

The main difference between the moderately optimistic scenario and the 'no-change' scenario is that the former is oriented to real structural and production shifts towards an increase in the amount of products for the domestic market, which provides import substitution. 
Another important condition for this scenario is the development of a stable and accessible domestic investment market that ensures intensive innovative development of the real sector of the economy. However, based on past experience, especially in 2007-2015, when, at high world prices for energy resources, favorable investment conditions for internal innovation development and restructuring of the real economy were missed, which led to the significant economic stagnation in Russia, which has been observed in recent years, the most likely scenario for the future economic development, at least in the period before 2035, is the 'no change' scenario. This scenario is of the greatest interest from the point of view of not optimistic (desirable), but minimum possible social and economic expectations, therefore, here the forecasting of the economic development is focused on this scenario.

\section{The preconditions for the macroeco- nomic forecast of the electricity con- sumption in the country and its eastern regions according to the 'no-change' scenario}

The basic condition for the macroeconomic forecast of the gross regional product of the country according to the 'no change' scenario is the unstable nature of the dynamics of the investment growth rates associated with the cyclicality of crises. This, accordingly, leads to an unstable growth rates of GRP production and to their relatively low average annual values.

The base year for the forecast is 2015. A general scheme of macro-forecasting of the economy and power consumption is shown in Fig. 1.

INVESTMENT IN THE CAPITAL ASSET OF RUSSIA: $I(t)=j(t) * I(t-1),(t=\overline{2015, \ldots, 2050})$, where:

$I(t)$ - investment in the fixed assets in the year $t ; j(t)$ - investment growth index in the year $t$

\begin{tabular}{|c|}
\hline $\begin{array}{l}\text { GROSS REGIONAL PRODUCT OF RUSSIA: } P(t)=k * I(t) \text {, where: } \\
P(t) \text { - gross regional product of the country in the year } t \text {; } k \text { - coefficient of rate of return in terms of GRP }(k=P / I) \text {,rub. } \\
\text { GROSS REGIONAL PRODUCT BY FEDERAL DISTRICT: } P_{f d}(t)=s_{f d} * P(t) \text {, where: } \\
P_{f d}(t)-\text { gross regional product of federal district in the year } t \\
s_{f d} \text { - share of the federal district in Russia's GRP, } \%\end{array}$ \\
\hline 1 \\
\hline $\begin{array}{l}\text { RUSSIA'S GRP ELECTRICITY INTENSITY: } \boldsymbol{e}(t)=j_{e}(t) * e(t-1), \mathrm{kWh} / \mathrm{rub} \text {, where: } \\
\boldsymbol{e}(t) \text { - GRP electricity intensity in the year } t ; j_{e}(t) \text { - index of decline in electricity intensity of Russia's GRP }\end{array}$ \\
\hline 7 \\
\hline $\begin{array}{c}\text { ELECTRICITY CONSUMPTION IN RUSSIA: } E(t)=\boldsymbol{e}(t) * P(t) \text {, where: } \\
E(t)) \text { - electricity consumption of the country in the year } t, k W h\end{array}$ \\
\hline$\downarrow$ \\
\hline $\begin{array}{c}\text { ELECTRICITY CONSUMPTION OF RUSSIA'S EASTERN REGIONS: } E_{f d}(t)=\mathrm{s}_{\mathrm{fde}} E(t) \text { where: } \\
E_{f d}(t)-\text { electricity consumption of the Federal District in the year } t, k W h ; \\
s_{f d e}-\text { share of the Federal District in electricity consumption of the country }(\%)\end{array}$ \\
\hline
\end{tabular}

Fig. 1. A General scheme of macroforecasting of the economy and electricity consumption in the country and its eastern regions

The calculation of prospective indicators of the national GRP production is linked to the investment through the investment return coefficients. Their value in dynamics has a small spread: in 2010 - 2016 it was within a range of 5.7-6.2 rub. [4]. This makes it possible to use its average value for the GRP forecasting (Fig. 2).

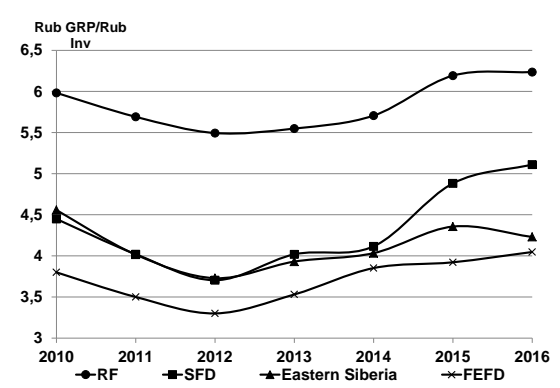

Fig. 2. The dynamics of investment return for GRP

Fig.3 demonstrates the dynamics of Russia's GRP production until 2050 which, like investment, is affected by crises. Despite the high growth rates of GRP in the phases of "recovery" during the crisis period (104-108\%), their average annual value from 2015 to 2050 is approximately $102.5 \%$.

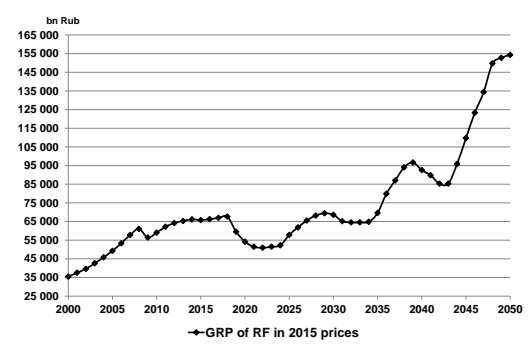

Fig. 3. The national GRP forecast

The observed stable structure of Russia's GRP by Federal District of the eastern regions allows us to assess the prospective levels of regional GRPs by means of a 
share-based disaggregation of the total GRP produced in the country (Figures 4, 5).

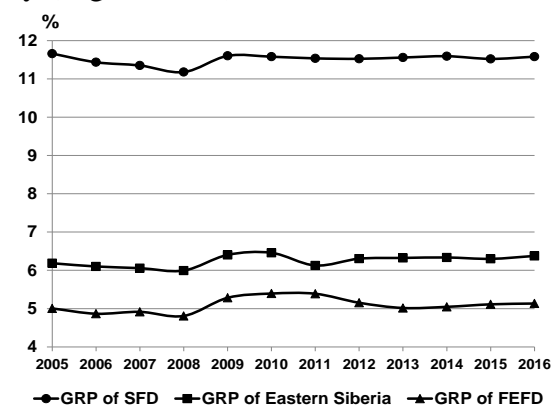

Fig. 4. Share of eastern regions in the GRP of the country

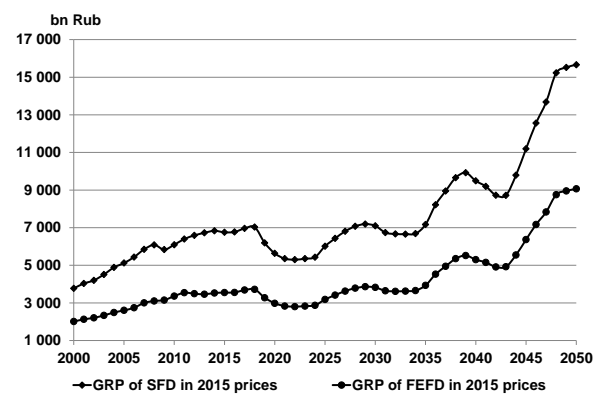

Fig. 5. GRP of the eastern regions

\section{The dynamics of GRP electricity inten- sity and the factors that affect it}

The level and dynamics of indicators of the electricity intensity of the production of various products and, accordingly, GRP depend on many factors. The main of them are:

- The improvement in production technologies (for example, according to some estimates, a $1 \%$ increase in spending on purchase of new equipment and advanced technologies by individual enterprises contributes to a decrease in the electricity intensity of production by $0.24 \%[5])$;

- The organizational and technological measures for energy conservation both in production, and in the service sector;

- The change in the structure of production in terms of an increase in the share of commodities produced by manufacturing industries, and especially the production of machinery, equipment, instruments, space and military equipment, etc., that are characterized by high added value and low energy intensity of production, or vice versa an increase in the share of energy intensive products (metallurgy, mining and beneficiation of minerals, chemical productions, etc.);

- The dynamics of and relationship between the prices for energy resources (it has an indirect effect associated with the transition to alternative energy resources or the need for energy-saving measures);

- The level of loading of production capacities and degree of wear and tear of fixed assets;

- The investment resources for upgrading of production, for technological innovations and energy saving, etc.

The electricity intensity of the national and regional GRP is a complex macro-indicator that reflects the cumulative effect of many social and production factors.
Whereas for an individual enterprise we can quite accurately determine the influence of each factor on the electricity intensity of the products produced by it, for the aggregate GRP electricity intensity, this is problematic, and, firstly, because of the incompleteness of all the necessary information. However, on the basis of available information and analysis of the most significant factors affecting the electricity intensity, their approximate contribution to the formation of the GRP electricity intensity and the trends in its changes, is assessed both in retrospect and in prospect.

The most important period for the analysis of the dynamics of GRP electricity intensity of Russia and its eastern regions is the last 15 years that reflect the market development of the economy, when economic entities have had an investment resource for the development and the sales markets have largely been determined. In these years, high world prices for energy resources and the flow of investment, both from the private and the budget sectors, have become an important factor in the development. The revival of production and economic activities in the country has also led to an increase in its effectiveness. An important indicator of this is the dynamics of the GRP electricity intensity in the country as a whole. The period of 8 years from 2000 to 2008 saw its decrease by $32 \%$, i.e. on average by $4.7 \%$ for each year. In 2009 2016, that is, from the year of the global financial crisis, the rate of decline slowed sharply and amounted to only $6.9 \%$, and on average $1.2 \%$ yearly. Similar dynamics of the change in the GRP electricity intensity for the first 8year period was typical of the Far East and Eastern Siberia. In the second period, in the Far Eastern Federal District, there was an increase instead of a decrease in the electricity intensity: by $9.5 \%$ - over the period, and by $1.3 \%$ - on average yearly (Fig. 6).

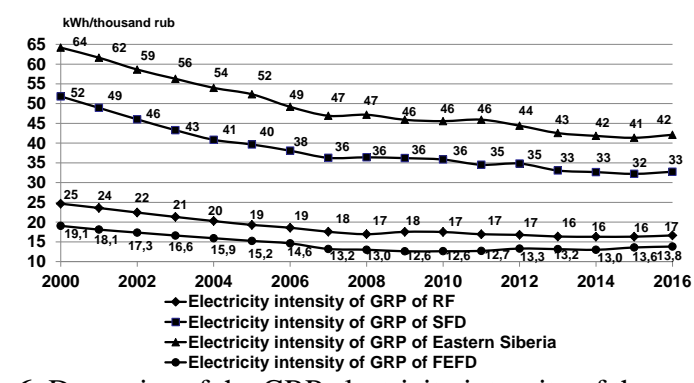

Fig. 6. Dynamics of the GRP electricity intensity of the country and its eastern regions

In 2008, the electricity intensity of the national GRP was $16.9 \mathrm{kWh} / \mathrm{rub}$ which is by $7.8 \mathrm{kWh} / \mathrm{rub}$ lower compared to 2000. In the crisis year 2009, it rose to 17.5 $\mathrm{kWh} / \mathrm{rub}$, by 2013 it amounted to $16.3 \mathrm{kWh} / \mathrm{rub}$, and has remained the same for all past years. This is explained by the crisis state of the economy and the influence of structural and production factors: a decrease in the capacity utilization, a decrease in the investment in the energy saving measures, the development of the energy intensive industries in the eastern regions, etc. In the emerging internal and external conditions, the cardinal changes towards favorable conditions are not expected until 20252030. After 2030-2035 only, there can be a moderate revival of the investment activity in the country, which will have a positive effect on the dynamics of GRP elec- 
tricity intensity. According to optimistic estimates, the GRP electricity intensity by 2050 will decrease to about $10 \mathrm{kWh} / \mathrm{rub}$, and according to more cautious forecasts up to $12.5 \mathrm{kWh} / \mathrm{rub}$.

\section{Forecast of electricity consumption in the country and its eastern regions}

The estimates of the electricity intensity dynamics were used to make a long-term forecast of the national electricity consumption up to 2050. In 2050, its value may reach 1575 billion $\mathrm{kWh}$, which is approximately 1.5 times the volume of electricity consumption in 2015. Electricity consumption in the eastern regions was estimated in terms of the unchanged shares of electricity consumption in the country (Fig. 7).

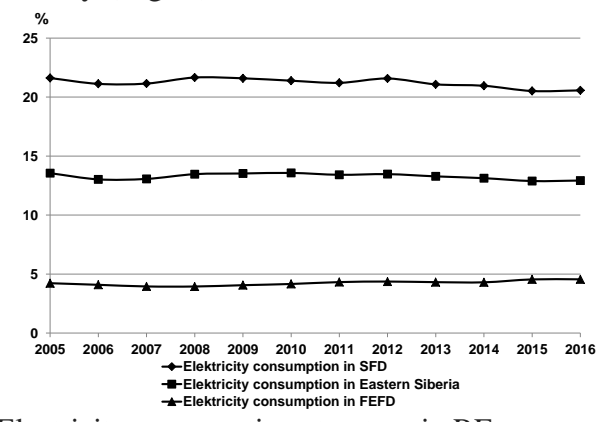

Fig. 7. Electricity consumption structure in RF

In the Siberian Federal District, the electric power consumption will amount to 315 billion $\mathrm{kWh}$ by 2050 , which is 1.4 times the volume of 2015, in Eastern Siberia - 215 billion kWh (1.6 times), and in the Far Eastern Federal District - 90 billion kWh (by a factor of 1.9) (Fig. 8).

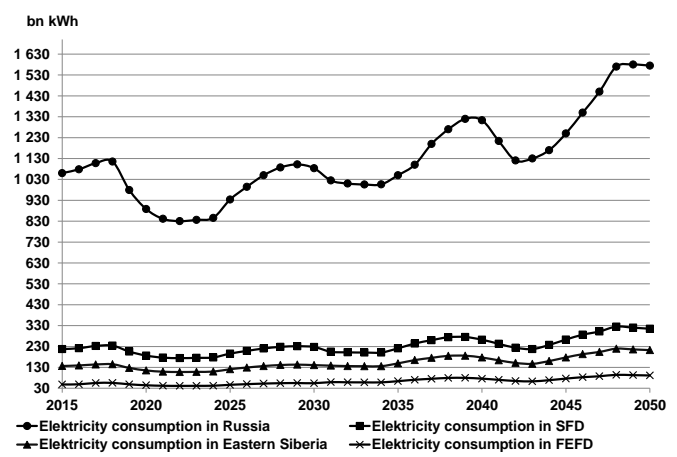

Fig. 8. Electricity consumption of RF and its eastern regions

Fig. 9 presents the data of the official forecast from the draft Energy Strategy of 2017 to compare the indicators of the electricity consumption forecast for the country and the eastern regions, given cyclical crises [6].

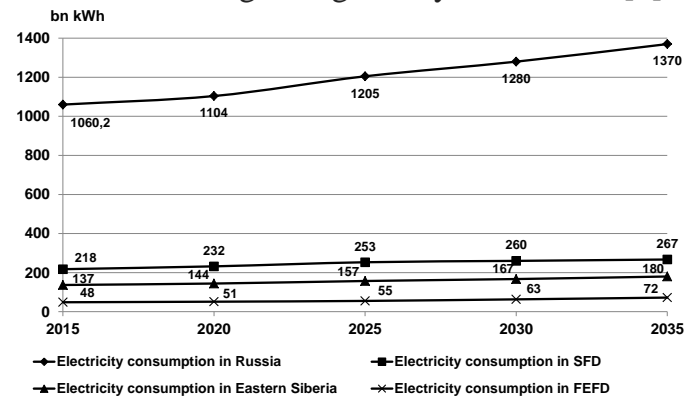

Fig. 9. Forecast of electricity consumption of the country and its eastern regions from the draft Energy Strategy of 2017
As evidenced from a comparison, the official forecast gives very optimistic levels of electricity consumption, which is poorly related to the current and forthcoming unfavorable conditions for the economic development of the country. According to the macroforecast from the 'no change' scenario presented in this paper, the level of official electricity consumption in the country in 2035 is reached only by 2045 .

\section{Conclusion}

The forecast level of electricity consumption in Russia and its eastern regions according to the 'no change' scenario can be used as a guide for the development of State and non-State Strategies and Programs for the long-term development of the national and regional energy sector, and its individual industries.

The work is done in the framework of the project III.174.2.2 program of fundamental research SB RAS, registration number AAAA-A17-117030310435-0

\section{References}

1. Kononov Yu.D. Ways to increase the validity of longterm forecasts of the energy development. Novosibirsk: Nauka, 2015, p. 34-36.

2. When to wait for a new world crisis. [Online]. Available: https://storm100.livejournal.com/3541359. html (Accessed June 27, 2018).

3. Types of cycles. Economic crises and their classification. [Online]. Available:

https://storm100.livejournal.com/3541359.html (Accessed June 27, 2018). - p. 5.

4. Korneev A.G. Monitoring of the current state of longterm forecasts of electricity consumption in the eastern regions of Russia and methodological issues of their improvement // Methodological problems in reliability study of large energy systems: Collected papers/ Ed. by N.I. Voropai, M.A. Korotkevich, A.A. Mikhalevich. Minsk: Publishing house BNTU, 2015. Issue 66, p. 125133.

5. Anisimova T.Yu. Influence of various factors on the achievement of strategic goals to reduce energy intensity of the domestic economy. [online] Available: https://kpfu.ru/docs/F929450089/2_Anis2.pdf (Accessed June 28, 2013), p. 4.

6. Draft Energy Strategy of the Russian Federation for the period up to 2035 (revised as of 01.02.2017). [online]. Available: https://minenergo.gov.ru/node/1920 (Accessed June 28, 2013). 